\title{
Fenugreek seed affects intestinal microbiota and immunological variables in piglets after weaning
}

\author{
Jürgen Zentek*, Stefanie Gärtner, Lydia Tedin, Klaus Männer, Anneluise Mader and Wilfried Vahjen \\ Department of Veterinary Medicine, Institute of Animal Nutrition, Freie Universität Berlin, 14195 Berlin, \\ Königin-Luise-Straße 49, Berlin, Germany
}

(Submitted 10 November 2011 - Final revision received 29 February 2012 - Accepted 6 March 2012 - First published online 3 July 2012)

\begin{abstract}
Fenugreek seed has been shown to affect the intestinal microbiota and immunological responses in animals. A feeding trial with male castrated piglets was performed over $28 \mathrm{~d}$ without or with the addition of $1.5 \mathrm{~g}$ fenugreek seeds $/ \mathrm{kg}$ complete diet in ten and eleven piglets, weaned at $21 \mathrm{~d}$. In the intestinal tract, $\mathrm{pH}$, lactate and SCFA were measured as major bacterial metabolites. Immune cell phenotypes, phagocytic activity and lymphocyte proliferation after stimulation with pokeweed mitogen, concanavalin A and phytohaemagglutinin $\mathrm{M}$ were measured by flow cytometry. Health status and performance of the piglets were not affected by fenugreek. The pH in the caecum and colon were reduced compared with the control $(P<0 \cdot 05)$. Higher concentrations of L-lactic acid were recorded in the small-intestinal digesta (average concentrations from the duodenum, jejunum and ileum; $P<0.05$ ), while the concentrations of SCFA remained unchanged except an increase in $n$-butyric acid in colon contents $(P<0.05)$. The piglets fed the fenugreek diet had higher Lactobacillus and clostridium cluster I concentrations and lower Escherichia, Hafnia and Shigella concentrations in the small intestine. The addition of fenugreek increased the relative concentration of the $\gamma \delta$ T-cell population (TCR $1^{+} \mathrm{CD} 8 \alpha^{-}$) in the blood with a simultaneous reduction of antigenpresenting cells $\left(\mathrm{MHCII}^{+} \mathrm{CD}^{-}\right)(P<0 \cdot 05)$. Proliferation rate and phagocytosis activity of monocytes were not affected by the additive. In conclusion, fenugreek seeds might be interesting as a feed ingredient for young piglets due to their effects on the intestinal microbiota and immunological variables. The impact on performance and animal health has to be further evaluated.
\end{abstract}

Key words: Piglets: Fenugreek: Lactate: SCFA: Lymphocytes

Fenugreek (Trigonella foenum graecum L.) is a legume mainly cultured in the Middle East and in Asia. Fractions of fenugreek have different therapeutic properties, for instance antidiabetic, cholesterol-lowering, antioxidant and anti-inflammatory effects $^{(1)}$. The seed is interesting as a dietary ingredient in human and animal nutrition due to some remarkable bioactive properties. Fenugreek seeds contain a variety of constituents. Those which are functionally interesting are mainly polysaccharides and flavonoids. They contain 32\% insoluble and $13.3 \%$ soluble fibre, and have high concentrations of galactose and mannose ${ }^{(2)}$. The galactomannan content of fenugreek varies depending on growth conditions and genotype and can be $12 \cdot 8-21 \cdot 5 \%{ }^{(3)}$. The hypoglycaemic and hypocholesterolaemic effects seem to be mainly linked with the specific composition and biological activity of carbohydrates and the high saponin content ${ }^{(1,4)}$. There is increasing evidence that fenugreek can affect immunological variables in humans and animals. Isolated galactomannans from fenugreek increased the phagocytic rate of peritoneal macrophages in rats ${ }^{(5)}$. The galactomannans used in the same study resulted in an activation of human lymphoma cells, increasing the secretion of IgM. The alkaline-extracted polysaccharide fraction was more effective to stimulate the phagocytic activity than the aqueous extract. In mice, the use of an aqueous fenugreek seed extract at 50, 100 and $250 \mathrm{mg} / \mathrm{kg}$ body weight had a dose-dependent effect on different immune parameters ${ }^{(6)}$. In obese rats, fenugreek-supplemented diets reduced liver weight and circulating levels of $\mathrm{TNF}-\alpha^{(7)}$. In a study with cyclophosphamide-treated rats, fenugreek alleviated leucopaenia, and increased weights and cellularity of lymphoid organs. Serum $\boldsymbol{\gamma}$-globulin levels and delayed type of hypersensitivity response were higher in treated rats compared with the control group ${ }^{(8)}$.

Recently, it has been shown that fenugreek addition to bacterial cultures from porcine colonic digesta resulted in a significant amount of acetate, propionate and butyrate formation $^{(9)}$. Besides their potential as a microbial substrate, galactomannans from fenugreek can effectively interfere with ganglioside GM1-binding sites of cholera toxin and of human and porcine Escherichia coli heat-labile enterotoxin ${ }^{(10)}$

Abbreviation: MHCII, major histocompatibility complex class II molecules.

*Corresponding author: Professor Dr J. Zentek, fax + 4930838 55983, email zentek.juergen@vetmed.fu-berlin.de 
3300; Fisher Scientific) using the Hoechst 33258 dye and calf thymus DNA as a reference. Cell numbers for the Escherichia group (Escherichia spp., Hafnia spp. and Shigella spp.) were detected with a Taqman assay ${ }^{(14)}$. Lactobacilli ${ }^{(15)}$, bifidobacteria $^{(16)}$, clostridium clusters I and $\mathrm{IV}^{(17)}$ as well as L. reuteri, L. johnsonii and L. amylovorus ${ }^{(18)}$ were detected using the stated published primer sequences. Streptococci were detected using the following primer combination, which was validated in the institute: Str1-f 5'-CCG CAT AAC AGC TTT TGA CA- $3^{\prime}$ and Str1-r $5^{\prime}$-GGT AGG CCG TTA CCC TAC CT- $3^{\prime}$. All primers were purchased from MWG Biotech. A Stratagene MX3000p (Stratagene) was used for PCR amplification and fluorescent data collection. The mastermix consisted of $12.5 \mu \mathrm{l}$ Brilliant SYBR Green QPCR Mastermix (Stratagene) or $12.5 \mu \mathrm{l}$ HotStartTaq Mastermix (Qiagen) for Taqman assays, $0.5 \mu \mathrm{l}$ of each primer $(10 \mu \mathrm{M}), 0.75 \mu \mathrm{l} 5$-carboxy-X-rhodamine (ROX) reference dye (1:500 diluted) and $10 \cdot 75 \mu \mathrm{l}$ water. Before PCR amplification, $1 \mu \mathrm{l}$ sample was added. All amplification programmes included an initial denaturation step at $95^{\circ} \mathrm{C}$ for $15 \mathrm{~min}$ to activate the polymerase. All PCR programmes featured an annealing time of $30 \mathrm{~s}$, and a $30 \mathrm{~s}$ extension at $72^{\circ} \mathrm{C}$. The annealing temperature was $50^{\circ} \mathrm{C}$ for Escherichia cell numbers, $55^{\circ} \mathrm{C}$ for lactobacilli, streptococci, both clostridium clusters as well as $L$. reuteri, and $58^{\circ} \mathrm{C}$ for bifidobacteria, L. johnsonii and L. amylovorus. As a quantification procedure $^{(19)}$, a series of autoclaved pig faecal samples were spiked with different bacterial species and known cell numbers $\left(10^{9}-10^{3}\right.$ cells/g wet weight). After extraction and purification, these extracts were used as PCR calibration samples, and the results were expressed as cell numbers/g sample wet weight.

\section{$\mathrm{pH}$ and bacterial metabolites in the digesta}

$\mathrm{pH}$ was measured in the digesta by a $\mathrm{pH}$ electrode connected to a $\mathrm{pH}$ meter (seven Multi; Mettler Toledo). D- and L-lactate concentrations in the digesta of intestinal contents were determined by a HPLC system (Agilent 1100; Agilent Technologies). For the analysis of lactate, $0.5 \mathrm{~g}$ digesta were mixed at a ratio of $1: 1$ with ice-cold $0.5 \mathrm{M}$-copper sulphate solution. After centrifugation, the supernatant was mixed with $50 \mu \mathrm{l}$ of $85 \mathrm{~mm}-\mathrm{K}_{4}\left[\mathrm{Fe}(\mathrm{CN})_{6}\right] \cdot 3 \mathrm{H}_{2} \mathrm{O}$ (Carrez I), and incubated on ice for $5 \mathrm{~min}$. Then, $50 \mu \mathrm{l}$ of $250 \mathrm{~mm}-\mathrm{ZnSO}_{4} .7 \mathrm{H}_{2} \mathrm{O}$ (Carrez II) were added and the samples were again incubated on ice for $5 \mathrm{~min}$. The supernatant was filtered through cellulose acetate syringe filters and separated on a Phenomenex Chirex 3126 (D)-penicillamine $(150 \times 4.6 \mathrm{~mm}$; Phenomenex Company) fitted with a Phenomenex pre-column (C18 $4.0 \mathrm{~mm} \times 2.0 \mathrm{~mm}$ inner diameter; Phenomenex Company). For the analysis of SCFA, $300 \mathrm{mg}$ digesta were diluted in distilled water, homogenised and centrifuged (Heraeus Instruments) at $13000 \mathrm{rpm}$ for $15 \mathrm{~min}$. Hexanic acid was used as an internal standard $(0.5 \mathrm{mmol} / \mathrm{l})$. The sample $(1.0 \mu \mathrm{l})$ was analysed by a gas chromatograph (Model 19095N-123; Agilent Technologies), fitted with a HP-INNOWax column A (length $30 \mathrm{~m}$, internal diameter $530 \mu \mathrm{m}$, with a film thickness of $1.0 \mu \mathrm{m}$ ). The initial temperatures of the oven, injector and FID detector were 70,230 and $250^{\circ} \mathrm{C}$. Hydrogen gas was used as a carrier gas (gas generator: Parker ChromGas; Parker Hannifin Corporation) at a flow rate of $30 \mathrm{ml} / \mathrm{min}$.

\section{Blood count}

Blood count was carried out with EDTA blood (Laboklin).

\section{Flow cytometry for immune cell phenotyping}

Peripheral blood mononuclear cells were isolated by density gradient centrifugation using Ficoll. Flow cytometry was carried out as described previously ${ }^{(20)}$. Staining of purified immune cell preparations for CD 4 and CD $8 \alpha$ was performed with labelled primary antibodies in a one-step incubation. All other immune cell antigens were detected using unlabelled primary antibodies followed by washing and incubation with a fluorescence-labelled secondary antibody (see below). Cells were assayed by flow cytometry using a FACSCalibur flow cytometer equipped with a $488 \mathrm{~nm}$ argon laser (FACS Calibur; Becton Dickinson).

Labelled primary antibodies used for flow cytometry are as follows: mouse anti-porcine CD4 clone 74-12-4, conjugated to fluorescein isothiocyanate; mouse anti-porcine CD8 $\alpha$ clone PT8, conjugated to R-phycoerythrin. Unlabelled primary antibodies used for flow cytometry are as follows: mouse anti-porcine CD2, clone MSA4 (kind gift from Professor A. Saalmüller, University of Veterinary Medicine Vienna, Vienna, Austria); mouse anti-porcine CD5, clone b53b7 (gift from Professor A. Saalmüller); mouse anti-porcine CD8 $\beta$ clone PG164A (VMRD); mouse anti-porcine CD14, clone MIL2 (Serotec); mouse anti-porcine CD21, clone BB6-11C9.6 (Southern Biotech); mouse anti-porcine CD25, clone K231.3B2 (Acris); mouse anti-porcine TcR1-N4 ( $\delta$-chain), clone PGBL22A (VMRD); mouse anti-porcine MHCII, clone MSA3 (VMRD); mouse anti-porcine CD45 RC, clone 3 a56 (gift from Professor A. Saalmüller); mouse anti-porcine CD172a, clone 74-22-15A (BD Pharmingen). Secondary antibodies are as follows: goat anti-mouse IgG, conjugated to fluorescein isothiocyanate or to phycoerythrin (PE) (Southern Biotech).

\section{Phagocytosis assay}

Phagocytosis of opsonised fluorescein isothiocyanate-labelled E. coli bacteria was measured using the commercial test kit Phagotest $^{\mathrm{TM}}$ following the instructions of the manufacturer (PHAGO-Test ${ }^{\circledR}$; ORPEGEN Pharma GmbH).

\section{Proliferation assay}

The assay was carried as follows: leucocytes $\left(4 \times 10^{5}\right.$ cells/ well) were cultured in ninety-six-well flat-bottom tissue culture plates. To stimulate peripheral blood mononuclear cells, pokeweed mitogen $(2.5 \mu \mathrm{g} / \mathrm{ml})$, concanavalin A $(5 \mu \mathrm{g} / \mathrm{ml})$ and phytohaemagglutinin $(10 \mu \mathrm{g} / \mathrm{ml})$ were used. Incubation was performed at $37^{\circ} \mathrm{C}$ and $100 \%$ relative humidity in a $5 \%$ $\mathrm{CO}_{2}$ atmosphere. After $48 \mathrm{~h}$ of incubation, bromodeoxyuridine $(60 \mu \mathrm{m})$ was added and cells were incubated under the same conditions for another $24 \mathrm{~h}$. To measure bromodeoxyuridine 
incorporation, cells were fixed with ethanol (10 min on ice). Cells were washed and stained with a fluorescein isothiocyanate-conjugated antibody (mouse anti-bromodeoxyuridine; BD Pharmingen ${ }^{\mathrm{TM}}$ ) according to the manufacturer's instructions. The incorporation was detected using a FACSCalibur flow cytometer (Becton Dickinson).

\section{Statistical analysis}

Statistical analysis was conducted using the statistical program PASW 18.0 (IBM). Data distribution was tested using the Kolmogorov-Smirnov test with Lilliefors correction. For normally distributed data, a two-sided $t$ test was performed. For non-normally distributed data, the Mann-Whitney test was applied. A $P$ value of $\leq 0.05$ was considered significant for all data. The experimental unit for the performance data (body weight, weight gain, feed intake and feed conversion) was the pen, and for the post-mortem data the individual.

\section{Results}

All animals showed an unimpaired general condition; diarrhoea did not occur. Initial body weight (8.23 (SD 0.78) $v$. $8.30(\mathrm{SD} 0.86) \mathrm{kg}$ ), final body weight $(16.71$ (SD 1.51) v. 17.43 $(\mathrm{SD} 1.30) \mathrm{kg})$, daily weight gain $(0.30 \quad(\mathrm{SD} 0.04) \quad v$. $0.33(\operatorname{sD~} 0.03) \mathrm{kg}$ ), daily feed intake $(0.59(\operatorname{sD} 0.10) v .0 .64$ $(\mathrm{SD} 0 \cdot 10) \mathrm{kg})$ and feed conversion (1.96 (SD 0.25) v. 1.95 (SD 0.24)) were comparable in the control group and the fenugreek group.

\section{$\mathrm{pH}$ and bacterial metabolites in the digesta}

Compared with the control group, the $\mathrm{pH}$ was reduced in the fenugreek group in the caecum and colon (Table 2). A significant difference between the control animals and the fenugreek group was observed in the L-lactic acid concentrations in the small intestine $(P<0 \cdot 05)$. The lactic acid concentration declined in the large-bowel digesta and was not different between the two groups. The total concentration of SCFA in the small intestine was very low and showed no feed-related differences. In the caecum, the levels of SCFA increased. However, absolute levels and the distribution of the acids were similar. In the colon digesta, butyric acid was higher in piglets fed the fenugreek diet compared with the control group $(P<0.05)$.

\section{Bacterial cell numbers in the jejunal and caecal digesta}

The bacterial cell numbers in the jejunum are shown in Table 3. Compared with the control diet, the counts of the Lactobacillus group were higher when feeding fenugreek ( $P=0.018$ ). A cell count increase was evident for L. jobnsonii $(P=0.016)$. The jejunal concentration of the Escherichia group was significantly reduced by the addition of fenugreek $(P=0 \cdot 048)$. Ingestion of fenugreek led also to increased cell numbers of clostridium cluster I $(P=0.048)$, while clostridium cluster XIV remained stable. In the caecum, $L$. reuteri and L. johnsonii were increased $(P=0.034$ and 0.016$)$ by the addition of fenugreek. The differences were only marginal for the other groups and species.

\section{Blood counts, immune cell phenotyping and proliferation assays}

Among the haematological parameters and the differential blood counts, no differences between the feeding groups were identified (data not shown). The piglets fed with fenugreek seed showed somehow altered composition of peripheral blood mononuclear cells (Table 4). The phenotypic analysis of circulating $\mathrm{T}$ cells showed a relative increase in $\mathrm{CD}^{-} \gamma \delta \mathrm{T}$ cells, while no changes were observed concerning the portions of circulating $\mathrm{CD}^{+} \gamma \delta \mathrm{T}$ cells. The percentages of

Table 2. $\mathrm{pH}$ and concentrations of $\mathrm{D}$ - and L-lactic acid and SCFA in the small intestine, caecum and colon digesta in piglets fed the control or fenugreek diet

(Mean values and standard deviations)

\begin{tabular}{|c|c|c|c|c|c|c|c|c|c|c|c|c|}
\hline \multirow{4}{*}{ Diet... } & \multicolumn{12}{|c|}{ Gut segment } \\
\hline & \multicolumn{4}{|c|}{ Small intestine $†$} & \multicolumn{4}{|c|}{ Caecum } & \multicolumn{4}{|c|}{ Colon } \\
\hline & \multicolumn{2}{|c|}{ Control } & \multicolumn{2}{|c|}{ Fenugreek } & \multicolumn{2}{|c|}{ Control } & \multicolumn{2}{|c|}{ Fenugreek } & \multicolumn{2}{|c|}{ Control } & \multicolumn{2}{|c|}{ Fenugreek } \\
\hline & Mean & SD & Mean & SD & Mean & SD & Mean & SD & Mean & SD & Mean & SD \\
\hline $\begin{array}{l}\mathrm{pH} \\
\text { Lactic acid (mmol/l) }\end{array}$ & $6 \cdot 1$ & $0 \cdot 61$ & $5 \cdot 4$ & 0.52 & $5 \cdot 7$ & 0.37 & $5 \cdot 3^{*}$ & 0.24 & $6 \cdot 0$ & 0.23 & $5 \cdot 5^{\star}$ & 0.36 \\
\hline $\mathrm{D}$ & $15 \cdot 8$ & $21 \cdot 5$ & $17 \cdot 4$ & $7 \cdot 80$ & $4 \cdot 81$ & $14 \cdot 6$ & $7 \cdot 31$ & $12 \cdot 6$ & \multicolumn{2}{|c|}{ ND } & \multicolumn{2}{|c|}{ ND } \\
\hline L & 24.5 & $13 \cdot 5$ & $40 \cdot 3^{*}$ & $17 \cdot 9$ & $4 \cdot 91$ & 4.42 & $7 \cdot 73$ & $12 \cdot 9$ & \multicolumn{2}{|c|}{ ND } & \multicolumn{2}{|c|}{ ND } \\
\hline \multicolumn{13}{|l|}{ SCFA } \\
\hline Total $(\mathrm{mmol} / \mathrm{l})$ & 2.40 & $2 \cdot 87$ & $4 \cdot 31$ & $3 \cdot 26$ & $101 \cdot 2$ & $22 \cdot 6$ & $106 \cdot 5$ & $21 \cdot 0$ & $110 \cdot 0$ & $15 \cdot 1$ & $111 \cdot 1$ & $21 \cdot 7$ \\
\hline Acetic acid (mol\%) & $82 \cdot 5$ & $6 \cdot 48$ & $77 \cdot 2$ & $6 \cdot 17$ & $57 \cdot 0$ & 4.04 & $55 \cdot 8$ & $3 \cdot 12$ & 58.4 & 3.75 & 55.4 & 4.65 \\
\hline Propionic acid (mol\%) & $10 \cdot 1$ & $5 \cdot 82$ & $10 \cdot 7$ & $5 \cdot 02$ & $29 \cdot 7$ & $3 \cdot 25$ & 30.5 & 3.98 & $26 \cdot 5$ & $4 \cdot 72$ & $26 \cdot 6$ & 3.55 \\
\hline i-Butyric acid (mol\%) & 0.77 & 2.05 & 0.73 & 0.91 & 0.90 & 1.97 & 0.36 & 0.24 & 0.68 & 3.57 & 0.68 & 0.55 \\
\hline$n$-Butyric acid (mol\%) & $2 \cdot 14$ & 1.76 & 3.68 & $2 \cdot 17$ & $9 \cdot 91$ & $2 \cdot 38$ & $11 \cdot 1$ & 2.99 & $11 \cdot 1$ & 1.72 & $13 \cdot 5^{\star}$ & $1 \cdot 32$ \\
\hline$i$-Valeric acid (mol\%) & 3.63 & 3.41 & $6 \cdot 66$ & $6 \cdot 97$ & 0.30 & 0.07 & 0.31 & 0.24 & 0.76 & 0.37 & 0.80 & 0.72 \\
\hline$n$-Valeric acid (mol\%) & 0.87 & 0.53 & 1.02 & 0.86 & $2 \cdot 18$ & 1.86 & 2.07 & $1 \cdot 13$ & 2.57 & 1.02 & 2.99 & $1 \cdot 12$ \\
\hline
\end{tabular}

ND, not determined

${ }^{*}$ Mean value was significantly different from that of the control group $(P<0.05)$

†Data represent the average concentrations from three sampling sites (duodenum, jejunum and ileum), except the $\mathrm{pH}$, that was measured in the proximal jejunum. 
Table 3. Bacterial groups and species in the jejunal and caecal digesta of piglets fed the control or fenugreek diet (Mean values and standard deviations)

\begin{tabular}{|c|c|c|c|c|c|c|c|c|}
\hline \multirow{3}{*}{ Diet... } & \multicolumn{4}{|c|}{ Jejunum } & \multicolumn{4}{|c|}{ Caecum } \\
\hline & \multicolumn{2}{|c|}{ Control } & \multicolumn{2}{|c|}{ Fenugreek } & \multicolumn{2}{|c|}{ Control } & \multicolumn{2}{|c|}{ Fenugreek } \\
\hline & Mean & SD & Mean & SD & Mean & SD & Mean & SD \\
\hline Bifidobacteria (log/g) & $6 \cdot 05$ & 1.02 & $6 \cdot 59$ & 0.49 & 7.07 & 0.56 & $7 \cdot 28$ & 0.71 \\
\hline Lactobacilli (log/g) & $7 \cdot 67$ & 0.56 & $8 \cdot 41^{*}$ & 0.74 & $9 \cdot 40$ & 0.57 & 9.67 & 0.53 \\
\hline L. amylovorus & $6 \cdot 92$ & 0.46 & $7 \cdot 34$ & 0.73 & $9 \cdot 72$ & 0.57 & $9 \cdot 74$ & 0.87 \\
\hline L. reuteri & $6 \cdot 55$ & 0.95 & $7 \cdot 67$ & 1.54 & 7.59 & 0.67 & $8 \cdot 27^{*}$ & 0.70 \\
\hline L. johnsonii & $7 \cdot 73$ & 0.60 & $8 \cdot 34^{*}$ & 0.41 & $8 \cdot 45$ & 0.40 & $9 \cdot 15^{\star}$ & 0.45 \\
\hline Escherichia/Hafnia/Shigella (log/g) & $5 \cdot 90$ & 0.56 & $5 \cdot 40^{*}$ & 0.48 & $7 \cdot 23$ & 0.99 & $7 \cdot 25$ & 0.71 \\
\hline Clostridium cluster I (log/g)† & $6 \cdot 09$ & 0.70 & $6 \cdot 99^{*}$ & $1 \cdot 22$ & $9 \cdot 05$ & 0.79 & $9 \cdot 08$ & $1 \cdot 24$ \\
\hline Clostridium cluster XIVa (log/g) $\ddagger$ & 6.53 & 1.53 & $6 \cdot 12$ & 0.96 & $10 \cdot 37$ & 0.35 & $10 \cdot 31$ & 0.36 \\
\hline Streptococci $(\log / g)$ & $7 \cdot 65$ & $0 \cdot 25$ & $7 \cdot 61$ & 0.28 & $8 \cdot 71$ & 0.71 & $8 \cdot 82$ & 0.49 \\
\hline
\end{tabular}

the other T-cell populations measured during the animal study $\left(\mathrm{CD}^{+}\right.$and $\left.\mathrm{CD}^{+}\right)$showed no clear alterations. NK cells $\left(\mathrm{CD} 2^{+} \mathrm{CD}^{-}\right)$also seemed to be unaffected. In the case of the antigen-presenting cells, a significant effect was observed in the outcome in that the percentage of major histocompatibility complex class II molecules (MHCII)-bearing CD5 cells was significantly reduced in the blood of the fenugreek group. Likewise, the median values of $\mathrm{CD} 14^{+}$cells (monocytes) and $\mathrm{SWC}^{+}$cells (all myeloid cells) were numerically lower in the group of fenugreek-treated piglets, while no changes were observed between the groups concerning the relative numbers of $\mathrm{CD}_{2} 1^{+}$cells (B cells) in the blood. The proliferation assays carried out with peripheral blood mononuclear cells from the different treated groups did not show

Table 4. Phenotypes of immune cells in the peripheral blood of piglets fed the control or fenugreek diet

(Medians and minimal (Min) and maximal (Max) measurements)

\begin{tabular}{|c|c|c|c|c|}
\hline \multirow[b]{3}{*}{ Lymphocytes (\%) } & \multicolumn{4}{|c|}{ Diet } \\
\hline & \multicolumn{2}{|c|}{ Control } & \multicolumn{2}{|c|}{ Fenugreek } \\
\hline & Median & Min-Max & Median & Min-Max \\
\hline $\mathrm{CD}^{+} \mathrm{CD}^{+}$ & 39.9 & $33 \cdot 6-49.6$ & 41.5 & $27 \cdot 1-47 \cdot 2$ \\
\hline $\mathrm{CD}^{+}{ }^{+} \mathrm{CD}^{-}$ & $22 \cdot 6$ & $10 \cdot 2-31 \cdot 3$ & $18 \cdot 0$ & $9.42-35.7$ \\
\hline $\mathrm{CD} 4^{+} \mathrm{CD} \beta^{-}$ & $16 \cdot 3$ & $8 \cdot 60-28 \cdot 4$ & $13 \cdot 4$ & $5.45-23.9$ \\
\hline $\mathrm{CD} 4^{+} \mathrm{CD}_{25}{ }^{+}$ & $3 \cdot 10$ & $0.83-4.88$ & $2 \cdot 20$ & $1.40-4.64$ \\
\hline $\mathrm{CD} \beta^{+}{ }^{+} \mathrm{CD} 4^{-}$ & $11 \cdot 3$ & $10 \cdot 0-24 \cdot 3$ & 13.9 & $9 \cdot 17-24 \cdot 0$ \\
\hline $\mathrm{TCR} 1^{+} \mathrm{CD} 8 \alpha^{+}$ & $3 \cdot 40$ & $1.93-7.60$ & $4 \cdot 10$ & $1.84-7 \cdot 13$ \\
\hline $\mathrm{TCR} 1^{+} \mathrm{CD} 8 \alpha^{-}$ & $9 \cdot 40$ & $3.92-20 \cdot 7$ & $17 \cdot 2^{*}$ & $7 \cdot 28-35 \cdot 0$ \\
\hline $\mathrm{CD} 14^{+}$ & $11 \cdot 3$ & $4 \cdot 16-23 \cdot 4$ & $6 \cdot 30$ & $3 \cdot 13-17 \cdot 2$ \\
\hline $\mathrm{CD}^{2} \alpha^{+} \mathrm{TCR}^{-}$ & $24 \cdot 8$ & $20 \cdot 7-39.9$ & $26 \cdot 2$ & $18 \cdot 3-43 \cdot 2$ \\
\hline $\mathrm{CD} 21^{+}$ & $16 \cdot 8$ & $8.78-22.9$ & $17 \cdot 3$ & $8.51-26.6$ \\
\hline $\mathrm{MHClI}^{+} \mathrm{CD}^{-}$ & 30.5 & $11 \cdot 2-43 \cdot 4$ & $20 \cdot 9^{*}$ & $16 \cdot 4-36 \cdot 0$ \\
\hline $\mathrm{CD} 45 \mathrm{RC}^{+}$ & 77.9 & $64.6-90.5$ & 83.5 & $74 \cdot 1-88 \cdot 7$ \\
\hline $\mathrm{CD} 5 \mathrm{RC}^{-}$ & $21 \cdot 7$ & $9 \cdot 44-35.4$ & $16 \cdot 2$ & $11 \cdot 1-25 \cdot 7$ \\
\hline
\end{tabular}

*Median value was significantly different from that of the control group $(P \leq 0.05)$. Mann-Whitney test was used for

non-normally distributed data. any alterations. Phagocytosis also was not affected by the feeding of the piglets (data not shown).

\section{Discussion}

Fenugreek seed has been previously described to have interesting properties affecting digestive function and the immune system of animals. We have demonstrated that fenugreek affected the intestinal microbiota as well as selected aspects of the immune function of piglets in the post-weaning period.

The administration of $1.5 \mathrm{~g}$ fenugreek seeds $/ \mathrm{kg}$ diet led to a lower $\mathrm{pH}$ of the digesta with significant diet-dependent changes in the caecum and colon of piglets. The $\mathrm{pH}$ reduction in the digesta by fenugreek seeds can display either an increase in the number of lactate-producing bacteria or their relevant metabolic activity. Fenugreek seeds contain over $50 \%$ carbohydrates in the $\mathrm{DM}^{(21)}$. Soluble galactomannans seem to be the most interesting fraction, while the amount of insoluble fibre is small ${ }^{(22)}$. The hydrophilic galactomannans have a high water-holding capacity and the ability to form viscous gels ${ }^{(1)}$, and seem to be a readily metabolisable substrate for the intestinal microbes, resulting in a higher production of organic acids. The concentrations of D-lactic acid were not affected by the seed. L-Lactic acid increased in the small intestine $(P<0.05)$, but was not influenced in the large intestine by fenugreek. This indicates that galactomannans are readily fermented in the upper gut by lactic acid bacteria and that lactic acid has been effectively metabolised in the large intestine by resident lactate-consuming bacteria. However, no increase in propionic acid and acetic acid was observed. These acids are the typical fermentation products of lactate fermentation $^{(23)}$. Using a porcine large-intestinal simulation model, the fermentability of fenugreek gum, containing $26 \cdot 2 \%$ galactose and $31.4 \%$ mannose, was also high and resulted in a high yield of acetate and butyrate. Lactic acid production was higher compared with flaxseed but considerably lower compared with the incubation of caecal microbes with 
$\beta$-glucans ${ }^{(9)}$. This difference might either indicate a lack of coincidence of data from in vivo and in vitro models or it can also be explained by different amounts of test substances and compositional varieties of fenugreek seeds. In particular, the content of galactomannans may vary depending on various factors $^{(3)}$. In rats, high levels of gums from fenugreek seed increased the concentrations of caecal SCFA, particularly propionic and acetic acid, and increased the caecal weight and the amount of water in the faeces. The higher propionic acid formation was correlated with a significant decrease in caecal $\mathrm{pH}^{(24)}$. In piglets, fenugreek seed, included at a considerably lower dietary level, had no effect on the total concentration and the pattern of SCFA in the small intestine and in the caecal digesta. Compared with the control group, the SCFA profile was similar. However, higher $n$-butyrate was seen in the colon contents of the fenugreek group. Next, to a general change in carbohydrate fermentation patterns, this may also indicate that a higher lactate concentration was available for $n$-butyrate-producing bacteria, which belong to heterogeneous clostridium clusters ${ }^{(25)}$. In the small intestine, a significantly increased L-lactate concentration as well as the strong numerical increases of lactobacilli, bifidobacteria and clostridium cluster I, which contains many butyrate-producing species, were observed. Thus, the increased $n$-butyrate formation may have been a result of increased lactic acid fermentation, which originated from the fermentation of soluble galactomannans in the upper gut. This finding is interesting due to the anticipated effects of butyrate as an energy-yielding substrate for the colonic epithelium in pigs ${ }^{(26,27)}$ and prospectively for humans.

Indigestible carbohydrates may alter the composition of the intestinal microbiota in pigs. In the present study, the modified bacterial fermentation metabolites were accompanied by a marked change in the microbiota in the jejunal and caecal digesta. With the addition of fenugreek seeds, an increase in lactobacilli and some major representatives of this genus, including L. johnsonii and, as a trend, L. reuteri, was observed. These changes show that fenugreek seeds had apparently substrate effects in the intestine, although the concentration in the diet was relatively low. Diets containing mannans and galactomannans from different sources have been shown to affect the intestinal microbes in pigs. Piglets fed a diet with mannan oligosaccharides from yeast had higher faecal lactobacilli counts compared with the control animals ${ }^{(28)}$. The increase in lactic acid-producing bacteria is interesting from the perspective of intestinal micro-ecology and due to the dietary impact on the occurrence of enterobacteria. A lower cell number of enterobacteria was observed in piglets after administration of fenugreek seeds. The change was not more than half a logarithm step, but was statistically significant. The addition of $0 \cdot 2 \%$ mannan oligosaccharides decreased enterobacteria concentrations in the jejunum digesta of piglets from $9 \cdot 1$ to $8 \cdot 0 \mathrm{log} / \mathrm{g}^{(29)}$. The impact of galactomannans from guar gum, locust bean gum or carob tree seed on the intestinal microbiota in pigs appeared inconsistent ${ }^{(30)}$. Total counts of bacteria were decreased by half a log unit in the proximal jejunum, while the number of $E$. coli increased in the stomach and in the jejunum. Increased ileal concentrations of total anaerobes, total aerobes, lactobacilli, enterobacteria and clostridia were determined in the ileum of piglets fed diets with very high concentrations $(7 \%)$ of guar gum ${ }^{(31)}$. From those findings, it can be concluded that the chemical composition of the indigestible carbohydrate fraction and the dietary inclusion level can have variable effects on the intestinal microbiota. Carbohydrates are considered to be most important, but other fractions of fenugreek seed, such as polyphenols, can have effects on the microbiota in pigs ${ }^{(32)}$. Regarding clostridia, a strong increase was observed for bacteria of clostridium cluster I in the small intestine, while clostridium cluster XIVa was not changed. Both clusters contain peptidolytic as well as saccharolytic species and therefore one cannot identify the exact net changes that occurred within both clusters. Proteolytic activities of the gut microbiota were not determined in the present study. However, given the increase in carbohydrate-fermenting lactic acid bacteria, it is conceivable that either saccharolytic clostridium species or lactate-fermenting clostridia gained an advantage.

The phenotyping of lymphocytes in the peripheral blood was characterised by a high variability of the data that is also known from other experiments with piglets ${ }^{(33-35)}$. This variability makes careful interpretation of the observed dietrelated differences mandatory. Fenugreek has been shown to affect immune variables in different animal models. The number of studies is scarce, but indicates some interesting effects. Galactomannans were able to affect phagocytosis in rat macrophages, and proliferation and IgM secretion in hybridoma cells ${ }^{(5)}$. In mice, cellular/humoral response variables and phagocytic capacity of macrophages were affected in a dose-related manner ${ }^{(6)}$. In rats, fenugreek alleviated symptoms of experimental immunosuppression ${ }^{(8)} \cdot \mathrm{CD}^{-} \gamma \delta \mathrm{T}$ cells were increased in piglets fed fenugreek compared with the control animals. Porcine $\gamma \delta \mathrm{T}$ cells have varying phenotypes and numerous functions, including a role in early responses against infections at epithelial surfaces, regulatory effects on different T-cell subsets and antigen-presenting cells, and are presumed to be crucial for both innate and specific immune responses in the young ${ }^{(36-39)}$. In the group of piglets fed with fenugreek seed, a significantly higher proportion of these so-called 'non-classical $\mathrm{T}$ cells, ${ }^{,(40,41)}$ was observed. In this group of piglets, $\mathrm{CD}^{-} \gamma \delta \mathrm{T}$ cells outnumbered the populations of helper $\mathrm{T}$ cells as well as cytotoxic T cells, which was not the case in the control group. 'Non-classical T cells' have been reported to constitute approximately 15-25\% of lymphocytes in the peripheral blood of pigs ${ }^{(42)}$, which is in line with the present results. Unfortunately, until now, little is known about the physiology of $\mathrm{CD}^{-} \gamma \delta \mathrm{T}$ cells. In contrast to $\mathrm{CD}^{+} \gamma \delta$ T cells, they do not respond to stimulation by mitogens including concanavalin $\mathrm{A}$, phytohaemagglutinin and pokeweed mitogen, neither to foreign antigens ${ }^{(43,44)}$. However, an extract from the plant Acanthospermum bispidum resulted in vitro in a proliferation of porcine $\mathrm{CD}^{-} \gamma \delta \mathrm{T}$ cells based on an IL-2-dependent mechanism mediated by CD 4 helper cells ${ }^{(45)}$. Both $\gamma \delta$ T-cell subpopulations are high in the young piglet and decrease during the growth period. Therefore, they are considered to be of special importance for the development and maturation of 
the juvenile immune system. The expression of the CD8 $\alpha$ molecule occurs after activation and is age-dependent, together with increasing MHCII expression ${ }^{(37)}$. The expansion of the $\mathrm{CD}^{-} \gamma \delta \mathrm{T}$ subset can be explained by the direct effects of fenugreek on the gut-associated immune system, or it might be the consequence of the observed changes in the intestinal microbiota. This finding makes fenugreek interesting as an immune-modulating ingredient. However, the characterisation of functional significance requires further studies and the influence on the health status of the animals cannot yet be assessed. Moreover, the same group of piglets showed another deviation in the composition of blood leucocytes. The portion of $\mathrm{MHCII}^{+} \mathrm{CD}^{-}$cells was significantly lower in the fenugreekfed group compared with the control group. As CD5 is expressed on all porcine $\mathrm{T}$ cells, this $\mathrm{CD}^{-}$MHCII-expressing population should be mainly $\mathrm{B}$ cells and monocytes. From the observation that the $\mathrm{CD} 21^{+}$population did not show any differences between the groups, we assume that the affected population is mainly composed of monocytes. This assumption is strengthened by the fact that the median values of $\mathrm{CD}_{14}{ }^{+}$cells and SWC3a (CD172a and SIRP $\alpha^{+}$) cells were also decreased in the fenugreek group.

In conclusion, fenugreek had interesting effects in piglets, lowering the $\mathrm{pH}$, and increasing the concentrations of lactic acid and lactobacilli in the digesta. Furthermore, the lower concentrations of enterobacteria indicate a change in the gut microbiota. The effects on the lymphocyte phenotypes in the peripheral blood of piglets have been noted. However, whether these findings affect colonisation resistance against invading pathogens and animal health has to be further evaluated.

\section{Acknowledgements}

This study was supported by Delacon Biotechnik GmbH, Steyregg, Austria. The contributions of each author are as follows: J. Z. contributed to the concept of the trial, supervision and writing of the manuscript; S. G. performed the practical work with the animal experiments and the laboratory work; L. T. contributed to the concept for the immunological methods and data evaluation; K. M. conducted the animal experiments, feed formulation and surveillance; A. M. contributed to the reviewing of the literature and manuscript; W. V. contributed to the microbiological work and the writing of the manuscript. The authors declare that there are no conflicts of interest.

\section{References}

1. Madar Z \& Stark AH (2002) New legume sources as therapeutic agents. Br J Nutr $\mathbf{8 8}$, S287-S292.

2. Roberts KT (2011) The potential of fenugreek (Trigonella foenum graecum) as a functional food and nutraceutical and its effects on glycemia and lipidemia. J Med Food 14, $1485-1489$.

3. Thomas JE, Bandara M, Lee EL, et al. (2011) Biochemical monitoring in fenugreek to develop functional food and medicinal plant variants. $N$ Biotechnol 28, 110-117.
4. Boban PT, Nambisan B \& Sudhakaran PR (2006) Hypolipidaemic effect of chemically different mucilages in rats: a comparative study. Br J Nutr 96, 1021-1029.

5. Ramesh HP, Yamaki K \& Tsushida T (2002) Effect of fenugreek (Trigonella foenum-graecum L.) galactomannan fractions on phagocytosis in rat macrophages and on proliferation and IgM secretion in HB4C5 cells. Carbohydr Polym 50, 79-83.

6. Bin-Hafeez B, Haque R, Parvez S, et al. (2003) Immunomodulatory effects of fenugreek (Trigonella foenum graecum L.) extract in mice. Int Immunopharmcol 3, 257-265.

7. Raju J \& Bird RP (2006) Alleviation of hepatic steatosis accompanied by modulation of plasma and liver TNFalpha levels by Trigonella foenum graecum (fenugreek) seeds in Zucker obese (fa/fa) rats. Int J Obes 30, 1298-1307.

8. Ramadan G, El-Beih NM \& Abd El-Kareem HF (2011) Antimetabolic syndrome and immunostimulant activities of Egyptian fenugreek seeds in diabetic/obese and immunosuppressive rat models. Br J Nutr 105, 995-1004.

9. Lin B, Gong J, Wang Q, et al. (2011) In-vitro assessment of the effects of dietary fibres on microbial fermentation and communities from large intestinal digesta of pigs. Food Hydrocoll 25, 180-188.

10. Becker PM, Widjaja-Greefkes HCA \& van Wikselaar PG (2010) Inhibition of binding of the AB5-type enterotoxins LT-I and cholera toxin to ganglioside GM1 by galactoserich dietary components. Foodborne Pathog Dis 7, 225-233.

11. NRC (1998) Nutrient Requirements of Swine, 10th revised ed. Washington, DC: National Academy of Sciences.

12. GfE (2006) Empfehlungen zur Energie- und Nährstoffversorgung bei Schweinen (Recommendations for Energy and Nutrient Supply in Pigs). Frankfurt (Main): DLG Verlag.

13. Naumann K \& Bassler R (1976) Methodenbuch Band III, die chemische Untersuchung von Futtermitteln (Methods of Chemical Analysis of Feed, vol. 3). Melsungen: NeumannNeudamm.

14. Lyons SR, Griffen AL \& Leys EJ (2000) Quantitative real-time PCR for Porphyromonas gingivalis and total bacteria. J Clin Microb 38, 2362-2365.

15. Walter J, Hertel C, Tannock GW, et al. (2001) Detection of Lactobacillus, Pediococcus, Leuconostoc, and Weissella species in human feces by using group-specific PCR primers and denaturing gradient gel electrophoresis. Appl Environ Microbiol 67, 2578-2585.

16. Rinttilä T, Kassinen A, Malinen E, et al. (2004) Development of an extensive set of $16 \mathrm{~S}$ rDNA-targeted primers for quantification of pathogenic and indigenous bacteria in faecal samples by real-time PCR. J Appl Microbiol 97, 1166-1177.

17. Song YL, Liu CX \& Finegold SA (2004) Real-time PCR quantitation of clostridia in feces of autistic children. Appl Environ Microbiol 70, 6459-6465.

18. Walter J, Tannock GW, Tilsala-Timisjarvi A, et al. (2000) Detection and identification of gastrointestinal Lactobacillus species by using denaturing gradient gel electrophoresis and species-specific PCR primers. Appl Environ Microbiol 66, 297-303.

19. Vahjen W, Taras D \& Simon O (2007) Effect of the probiotic Enterococcus faecium NCIMB10415 on cell numbers of total Enterococcus spp., E. faecium and E. faecalis in the intestine of piglets. Curr Issues Intest Microbiol 8, 1-7.

20. Schierack P, Filter M, Scharek L, et al. (2009) Effects of Bacillus cereus var. toyoi on immune parameters of pregnant sows. Vet Immunol Immunopatbol 127, 26-37.

21. Billaud C \& Adrian J (2001) Fenugreek: composition, nutritional value and physiological properties. Sci Alim 21, 3-26. 
22. Madar Z \& Shomer I (1990) Polysaccharide composition of a gel fraction derived from fenugreek and its effect on starch digestion and bile-acid absorption in rats. J Agric Food Chem 38, 1535-1539.

23. Seeliger S, Janssen PH \& Schink B (2002) Energetics and kinetics of lactate fermentation to acetate and propionate via methylmalonyl-CoA or acrylyl-CoA. Fems Microbiol Lett 211, 65-70.

24. Evans AJ, Hood RL, Oakenfull DG, et al. (1992) Relationship between structure and function of dietary fibre - a comparative-study of the effects of 3 galactomannans on cholesterol-metabolism in the rat. Br J Nutr 68, 217-229.

25. Pryde SE, Duncan SH, Hold GL, et al. (2002) The microbiology of butyrate formation in the human colon. Fems Microbiol Lett 217, 133-139.

26. Claus R, Losel D, Lacorn M, et al. (2003) Effects of butyrate on apoptosis in the pig colon and its consequences for skatole formation and tissue accumulation. J Anim Sci 81, 239-248.

27. Tsukahara T, Iwasaki Y, Nakayama K, et al. (2003) Stimulation of butyrate production in the large intestine of weaning piglets by dietary fructooligosaccharides and its influence on the histological variables of the large intestinal mucosa. J Nutr Sci Vitaminol (Tokyo) 49, 414-421.

28. White LA, Newman MC, Cromwell GL, et al. (2002) Brewers dried yeast as a source of mannan oligosaccharides for weanling pigs. J Anim Sci 80, 2619-2628.

29. Castillo M, Martin-Orue SM, Taylor-Pickard JA, et al. (2008) Use of mannan-oligosaccharides and zinc chelate as growth promoters and diarrhea preventative in weaning pigs: effects on microbiota and gut function. J Anim Sci 86, 94-101.

30. Van Nevel CJ, Decuypere JA, Dierick NA, et al. (2005) Incorporation of galactomannans in the diet of newly weaned piglets: effect on bacteriological and some morphological characteristics of the small intestine. Arch Anim Nutr 59, $123-138$

31. Owusu-Asiedu A, Patience JF, Laarveld B, et al. (2006) Effects of guar gum and cellulose on digesta passage rate, ileal microbial populations, energy and protein digestibility, and performance of grower pigs. J Anim Sci 84, 843-852.

32. Hara H, Orita N, Hatano S, et al. (1995) Effect of tea polyphenols on fecal flora and fecal metabolic products of pigs. $J$ Vet Med Sci 57, 45-49.
33. Scharek L, Altherr BJ, Tolke C, et al. (2007) Influence of the probiotic Bacillus cereus var. toyoi on the intestinal immunity of piglets. Vet Immunol Immunopathol 120, 136-147.

34. Binter C, Khol-Parisini A, Hellweg P, et al. (2008) Phenotypic and functional aspects of the neonatal immune system as related to the maternal dietary fatty acid supply of sows. Arch Anim Nutr 62, 439-453.

35. Boudry C, Dehoux JP, Wavreille J, et al. (2008) Effect of a bovine colostrum whey supplementation on growth performance, faecal Escherichia coli population and systemic immune response of piglets at weaning. Animal 2, 730-737.

36. Takamatsu HH, Denyer MS, Stirling C, et al. (2006) Porcine gamma delta $T$ cells: possible roles on the innate and adaptive immune responses following virus infection (Special issue: Innate immunity and vaccination). Vet Immunol Immunopathol 112, 49-61.

37. Gerner W, Kaser T \& Saalmüller A (2009) Porcine T lymphocytes and NK cells - an update (Special Issue: The porcine immune system). Dev Comp Immunol 33, 310-320.

38. Hao J, Wu X, Xia S, et al. (2010) Current progress in $\gamma \delta \mathrm{T}$-cell biology. Cell Mol Immunol 7, 409-413.

39. Wen K, Li GH, Zhang W, et al. (2011) Development of gamma delta $\mathrm{T}$ cell subset responses in gnotobiotic pigs infected with human rotaviruses and colonized with probiotic lactobacilli. Vet Immunol Immunopathol 141, 267-275.

40. Saalmüller A, Hirt W \& Reddehase MJ (1990) Porcine gamma-sigma-lymphocyte-T subsets differing in their propensity to home to lymphoid-tissue. Eur J Immunol 20, 2343-2346.

41. Binns RM, Duncan IA, Powis SJ, et al. (1992) Subsets of null and gamma-delta-T-cell receptor + lymphocytes-T in the blood of young-pigs identified by specific monoclonalantibodies. Immunology 77, 219-227.

42. Yang H \& Parkhouse RME (1996) Phenotypic classification of porcine lymphocyte subpopulations in blood and lymphoid tissues. Immunology 89, 76-83.

43. Hammerberg C \& Schurig GG (1986) Characterization of monoclonal-antibodies directed against swine leukocytes. Vet Immunol Immunopathol 11, 107-121.

44. Binns RM (1994) The null/gamma-delta-Tcr(+) T-cell family in the pig. Vet Immunol Immunopathol 43, 69-77.

45. Summerfield A \& Saalmüller A (1998) Interleukin-2 dependent selective activation of porcine $\gamma \delta \mathrm{T}$ lymphocytes by an extract from the leaves of Acanthospermum bispidum. Int J Immunopharmacol 20, 85-98. 